\title{
Przede wszystkim o paratekstualności i remediacjach ${ }^{1}$
}

Łukasz Androsiuk

TEKSTY DRUGIE 2017, NR 1, S. 118-127

DOI: $10.18318 /$ td.2017.1.9

$\mathbf{T}$ ak się złożyło, że Media, wersja beta... czytałem na zmianę z Gödel. Życie i logika². Jednak to za sprawą tej drugiej zrozumiałem, co właściwie i dlaczego chce nam powiedzieć autor tej pierwszej. Jeśli bowiem twierdzenie austriackiego matematyka w jego uproszczonej wersji głosi, że „w każdym niesprzecznym systemie formalnym obejmującym arytmetykę istnieją arytmetyczne prawdy, których nie można udowodnić w ramach tego systemu"3, to kluczową tezę Mirosława Filipiaka, sformułowaną w jego książce, możemy wyrazić następująco: mimo że coś takiego jak kultura medialna rzeczywiście istnieje, to nie da się o niej mówić wyłącznie jej językiem.

To dlatego perspektywa kulturoznawcza (a nie, jak mógłby sugerować tytuł książki - medioznawcza)

1 Recenzja książki: M. Filiciak Media, wersja beta. Film i telewizja w czasach gier komputerowych, Wydawnictwo Naukowe Katedra, Gdańsk 2013, s. 312.

2 J.E. Casti, W. DePauli Gödel.Życie i logika, przeł. P. Amsterdamski, Wydawnictwo CiS, Warszawa 2003.

Łukasz Androsiuk adiunkt w Zakładzie Pedagogiki Ogólnej i Podstaw Edukacji w Instytucie Pedagogiki i Pracy Socjalnej Akademii Pomorskiej w Słupsku, członek Polskiego Towarzystwa Badania Gier. Ostatnio opublikował: Przyjemność kontrolowana. Wokół kategorii władzy, płci, autorytetu, oporu w kontekście badań ludologicznych (2015), Noël Carrol kontra ludolodzy. Gry wideo w perspektywie klasyfikacyjnej teorii sztuki masowej (2015). Kontakt: jozef314@ wp.pl

3 Tamże, s. 54 
stanowi dla autora Media, wersja beta... właściwy punkt odniesienia. Jest to o tyle istotne, że jeśli już na pierwszych stronach Filiciak poświęca sporo miejsca idei transdyscyplinarności, to bardziej dlatego, że ważniejsze od założeń metodologicznych są dla niego następstwa ontologiczne. Nie chodzi więc wyłącznie (a nawet nie przede wszystkim) o fakt, że „transdyscyplinarność dotyczy [...] tego, co jest zarazem między dyscyplinami, poprzez rozmaite dyscypliny jednocześnie poza każdą z nich”, lecz o to, że „przyjęcie perspektywy transdyscyplinarnej uzasadnia także sposób definiowania mediów traktowanych tu [...] jako dynamiczne, wielowymiarowe środowisko aktywności ludzi”" Pragnę zaakcentować te słowa ze zdwojoną siłą, bowiem to właśnie "dynamiczność”, ,wielowymiarowość” i „praktyka społeczna” stanowią klucz do zrozumienia tego, co autor ten właściwie ma na myśli, podejmując się refleksji nad „medialnym ekosystemem”, ale też „przemysłem kulturalnym”, "przemysłem medialnym”, a nawet (z powodów formalno-instytucjonalnych) „przemysłem rozrywkowym”.

Jeśli więc „dynamiczność”, to dlatego, że mowa tu o zjawiskach, które analogicznie do oprogramowania komputerowego podlegają ciągłej aktualizacji. Medialny ekosystem stanowi bowiem dla Filiciaka (i to zarówno w jego wymiarze materialnym, jak i niematerialnym) nie tyle zjawisko par excellence, ile proces. Oznacza to, że mamy tu do czynienia nie z czymś, co już „istnieje”, ale z czymś, co dopiero „staje się", przy czym owo „stawanie się" jest (ze względu na szczególnie dynamiczną naturę samych mediów) czymś zawsze niedokończonym. Jeśli zaś „,wielowymiarowość”, to dlatego, że nie istnieje i nie może istnieć jedyna słuszna i uprzywilejowana metodologicznie perspektywa, która miałaby zdominować refleksję nad kulturą medialną. Przemawiać za tym mają przede wszystkim argumenty natury epistemologicznej, które z oczywistych powodów ponownie nie mogą być wolne od uprzedzeń ontologicznych. Nie chodzi więc jedynie o fakt, że w przypadku medialnego ekosystemu mamy do czynienia z wielowymiarowością, lecz o to bardziej jeszcze, że nieustannie towarzyszy mu sygnalizowana w poprzednim zdaniu dynamiczność.

To dlatego właśnie powiada Filiciak, że zadanie, jakie sobie stawia przy okazji Media, wersja beta..., nie polega na tym, by "gonić" za tym, co nowe i spektakularne, ale na tym, aby „problematyzować” i podawać w wątpliwość to, co w kontekście badań nad kulturą medialną uchodzi za oczywistość „[...] wskazując, że ta zmiana jest równocześnie nieprzerwanym procesem negocjowania i konstruowania tego, co rozumiemy jako 'media'. Tak postawione

4 M. Filiciak Media, wersja beta..., s. 27-28. 
zadanie prowadzi [...] [M. Filiciaka - Ł.A.] w stronę całej sieci powiązań. Urządzenia, treści ich twórcy i konsumenci - jaki wywierają na siebie wpływ? [...] Wreszcie: na ile zmiana medialnego ekosystemu redefiniuje czy wręcz falsyfikuje dotychczasowe teorie mediów?"5. Jak zarazem jednak przekonuje autor, jeśli rzeczywiście zależy nam na „uczciwej” odpowiedzi na sformułowane w ten sposób pytania, jako badacze medialnego ekosystemu jesteśmy zobowiązani „wyjść zza biurka” i szukać nie tego, co chcemy znaleźć, ale tego, co faktycznie okazuje się owocem naszych wolnych (na ile i o ile to możliwe) od uprzedzeń dociekań i refleksji.

Od razu więc powiedzmy, że postulat ten - inspirowany bezpośrednio socjologią praktyk społecznych Nicka Couldry'ego - ma szczególnie doniosłe znaczenie zarówno dla przyjętej przez autora perspektywy badawczej, jak i wszystkiego, co w sferze przedmiotu swoich badań takowa perspektywa implikuje. Po pierwsze dlatego, że owo „wyjście zza biurka” oznacza dla Filiciaka niezgodę na perspektywę zdominowaną przez paradygmat funkcjonalny, , [...] uprzywilejowujący instytucje medialne i często przeceniający ich oddziaływanie"6. Po drugie zaś, chodzi „[...] o dostrzeżenie i dopuszczenie do głosu 'zwykłych użytkowników'"'. Nie bez znaczenia jest tu przymiotnik „zwykły”, bowiem odnosi się on także do zaangażowanego w projekt badacza. Ten ostatni nie ma już prawa stawiać siebie „poza”, a już na pewno nie „ponad” tymi, których bada. Konsekwencją tego stanu rzeczy jest to, że badacz takowy nie ma już rozstrzygającego zdania w związku z pytaniem o "prawidłowy” kształt badanej przestrzeni, kultury, rytuałów. W takim ujęciu medialny ekosystem nie ogranicza się już do (a często nawet nie dotyczy w ogóle) pytania o „formalne znaczenie”, (tekstualność) medialnych artefaktów, ale o ich „realne użycie”.

Jak powiada Couldry, „[...] chodzi o teoretyczne ramy patrzenia na media jako praktyki, a nie jak na tekst czy proces produkcji"8. Oznacza to, że z faktu, iż "Jan idzie do kina”, niekoniecznie wynika, że "Jan idzie na film", choć taki właśnie wniosek należałoby sformułować, reprezentując perspektywę funkcjonalną. Oczywiście „wyjście zza biurka” nie oznacza, że na gruncie badań medialnego ekosystemu kino jako takie przestaje być miejscem,

5 Tamże, s. 10.

6 Tamże, s. 43.

7 Tamże.

8 N. Couldry Media w kontekście praktyk. Próba teoretyczna, "Kultura Popularna” 2010 nr 1 (27), S. 111. 
gdzie ogląda się filmy, lecz że w kontekście praktyki związanej z oglądaniem filmów przestaje być ono instytucjonalnie uprzywilejowane. Wszakże sugerując się naszym codziennym doświadczeniem, zupełnie zasadnie wolno przecież twierdzić, że filmy oglądamy obecnie nie tylko - a być może nawet nie przede wszystkim - w kinie, ale choćby za sprawą wysokiej jakości odtwarzaczy DVD/Blu-ray (nie bez powodu określanych mianem „kina domowego") właśnie w domu. Co więcej; dzięki wielofunkcyjnym i coraz bardziej zaawansowanym pod względem technologicznym smartfonom należy dopowiedzieć, że właściwie gdziekolwiek ${ }^{9}$.

To dlatego właśnie w świetle socjologii praktyk społecznych uzasadniony okazuje się pozornie tylko przewrotny wniosek, zgodnie z którym „[...] widownia jest 'wszędzie' i nigdzie"10. Nieporozumieniem byłoby jednak sądzić, że zaproponowana przez Couldry'ego perspektywa ostatecznie unieważnia badania nad kulturą medialną (ze szczególnym uwzględnieniem historii mediów) uprawiane w duchu innym niż jego autorski paradygmat. Choć dodam od razu, że nieuważny i ideologicznie uprzedzony czytelnik (jakim sam pierwotnie się okazałem) autora socjologii praktyk społecznych, jak i Media, wersja beta..., taki właśnie wniosek mógłby rzeczywiście wyciągnąć.

Nie chodzi więc o to, że za formalnie bezwartościowe uznaje Couldry (a za nim Filiciak) wszelkie próby teoretycznego uchwycenia medialnego ekosystemu, ale o, po pierwsze, towarzyszącą każdemu badaczowi świadomość tego, że teorie takowe zawsze wyrastają z określonej tradycji intelektualnej, co sprawia, że tradycją tą obciążane są już na gruncie samego języka, na którym spoczywa nie tylko ciężar deskryptywności, ale i (co szczególnie ważne) normatywności. Po drugie zaś, że próby takowe nigdy nie sprowadzają się wyłącznie do tego, co jest mediów bezpośrednim przedmiotem. To dlatego właśnie tak szczególnie mocno podkreśla Couldry fakt, że z punktu widzenia badacza teorii praktyk medialnych - w znaczeniu, jakie sam nadaje temu pojęciu - bliżej mu do nauk społecznych niż wąsko rozumianego medioznawstwa. Jak sam bowiem dodaje, chodzi w istocie o

stawianie otwartych pytań o to, co ludzie robią, i jak kategoryzują to, co robią. [...] Jedną z możliwości, na które musimy być przygotowani, jest

9 Do podobnych wniosków doszli zresztą również autorzy raportu dotyczącego projektu badawczego "Młodzi i Media”, którym Filiciak kierował i który w kontekście Media, wersja beta... stał się właśnie przedmiotem pogłębionej refleksji. Por. M. Filiciak Media, wersja beta..., s. 43-57. 
to [...], że w wielu przypadkach 'konsumpcja mediów' czy 'widzowanie' mogą być rozumiane wyłącznie jako część praktyki, której ‘tematem' nie są media [...]. Oglądanie meczu piłki nożnej w telewizji w przypadku jednej osoby może być najtrafniej analizowane jako element jego/jej silnie emocjonalnej praktyki bycia fanem/fanką piłki nożnej, lub też fanem/ fanką konkretnej drużyny; dla kogoś innego, może to być obowiązek [...]. Wyraźnie widać, że badanie różnorodności tego, jak ludzie odczytują tekst danej gry w telewizji ani struktura transmitowanego tekstu gry nie mogą być głównymi priorytetami badania mediów. Bardziej interesująca jest analiza, po pierwsze, zakresu praktyk, w których czynność oglądania meczu piłki nożnej występuje, a po drugie, konsekwencji, jakie dla związków pomiędzy tymi praktykami mają cechy wspólne."

Na szczęście w swoich uwagach na temat medialnego ekosystemu Filiciak nie ogranicza się wyłącznie do perspektywy właściwiej socjologii praktyk społecznych Couldry'ego. Byłoby to zresztą niemożliwe, gdy ma się na uwadze już choćby zobowiązujący pod tym względem tytuł książki, za sprawą którego autor powiada wprost, że będą go interesować przede wszystkim „Film i telewizja w czasach gier komputerowych i internetu". Nawet jeśli więc (mając na myśli medialny ekosystem), Filiciaka interesuje bardziej „[...] relacja, w jakiej pozostają z mediami jej użytkownicy"12 niż media same w sobie, to doskonale zdaje on sobie zarazem sprawę, że siłą rzeczy opowiedzieć musi się nie tylko za określoną wizją „użytkownika” (w czym pomaga mu oczywiście Couldry), ale i samych "mediów" - co zresztą czyni z powodzeniem, dowodząc przy tym swojej ogromnej wiedzy kulturoznawczej i medioznawczej.

Punkt wyjścia dla charakterystyki zjawisk związanych z paratekstualnością, ale i z pytaniem o istotę, kształt oraz kierunek przemian mediów stanowi dla Filiciaka rozdział Gra w kino, który jest całkiem odważną i wciąż względnie rzadką próbą nie tylko „spojrzenia na kino”, ale i „doświadczenia kina” na nowo. Od razu warto dodać, że owo "na nowo” oznacza w tym względzie przede wszystkim „[...] odejście od modernistycznego przekonania o 'czystości' mediów"13. Nie chodzi tu jednak wyłącznie o fakt, że współcześn(i)e kino pod względem strukturalno-konstrukcyjnym przestaje być dla siebie oraz

Tamże, s. 107. 
(być może w większym jeszcze stopniu) dla jego odbiorców podstawowym (jeśli w ogóle jakimkolwiek) punktem odniesienia, ale bardziej o to jeszcze, że zaczyna odwoływać się do "nowych” - choć jak się okazuje dobrze już znanych - form medialnych.

W ten sposób konfrontuje Filiciak sztukę filmową przede wszystkim ze sztuką gier komputerowych ${ }^{14}$, która - jak przekonuje (i z czym trudno zresztą się nie zgodzić) - jest „[...] ikonicznym przykładem nowego, interaktywnego medium, w którym często istotną rolę odgrywa narracja i które z kinem prowadzi nieustanny dialog"15. Nie bez powodu zatem, mając na uwadze relację kino - gra komputerowa, pozwalam sobie w tym miejscu na zabieg stylistyczny w związku ze słowem „współcześn(i)e”. Nade wszystko pragnę bowiem tym samym podkreślić fakt, że Filiciak koncentruje się nie tylko na „współczesnym” kinie, ale i na kinie „współcześnie” pojmowanym i odczytywanym, zachęcając zarazem do refleksji nad historią tego medium. Historią, która nie byłaby jednak zakładnikiem swojej tradycji i parad(o) ygmatu, z którego wyrasta, tj. dla której wynalazek braci Lumière nie byłby jedynym uprawnionym konceptualnie punktem odniesienia. W świetle takiego postulatu istota zjawiska, o którym mowa, nie sprowadza się więc do popularnej tezy, zgodnie z którą kino „współczesne” ulega ze strony kultury gier komputerowych procesom remediacyjnym, że - innymi słowy - współczesne produkcje filmowe w swojej tekstualności i estetyce coraz częściej przypominają gry komputerowe. Nie chodzi również o proste stwierdzenie faktu, że współczesne kino coraz chętniej adaptuje gry wideo, tworząc na ich podstawie najczęściej wysokobudżetowe spektakularne widowiska. To, o co upomina się Filiciak, proponuję rozumieć jako upomnienie się o radykalną zmianę perspektywy związanej z hermeneutyką doświadczenia filmowego.

Upraszczając rzecz przesadnie, można powiedzieć, że chodzi tu o zredefiniowanie takiego doświadczenia, dla którego podstawową kategorią nie będzie odtąd wyłącznie „oglądanie” (perspektywa widza), tylko również „działanie”, ,operowanie” (perspektywa gracza komputerowego/konsolowego).W konsekwencji potencjał tekstu nie sprowadza się już wyłącznie do „interpretacji”, ale wzbogaca go „symulacją”. Jak opowiada Filiciak, „[...] sam doświadczyłem tego na przykładzie filmu Biegnij, Lola, biegnij Toma Tykwera

14 Sformułowaniem „sztuka gier komputerowych" posługuję się w tym miejscu prawdopodobnie nieco na wyrost i być może nawet wbrew woli autora recenzowanej tu książki. W istocie bowiem M. Filiciak w swojej pracy ani razu nie używa zwrotu "sztuka" w odniesieniu do gier wideo. 
z roku 1999; gdy jako student rozmawiałem o nim niedługo po premierze z wykładowcami, przedstawiono go jako wariację na temat Przypadku Krzysztofa Kieślowskiego (1987); dzisiaj moi studenci przeważnie widzą w strukturze narracyjnej tego filmu, opartej na trzykrotnym powtórzeniu zmagań głównej bohaterki z czasem, kopię struktury narracyjnej z czasem"16.

Doświadczenie, o którym powiada Filiciak, powinno mieć o wiele głębsze, a nawet zobowiązujące pedagogicznie znaczenie. Głębsze, ponieważ stanowi bardzo silny argument na rzecz tzw. zasady koła hermeneutycznego (każdy tekst poprzedza kontekst), a jeśli zobowiązujące, to dlatego, że uczula na to, co (nie tylko) pedagodzy lubią określać mianem „procesu negocjowania znaczeń". Chodzi wszakże o proces, którego istotą jest „nadawanie” nowych znaczeń, które (co szczególnie ważne) niekoniecznie są względem siebie opozycyjne, lecz komplementarne. Jeśli zaś tak mocno podkreślam pedagogiczne znaczenie zjawiska, o którym mowa, to nade wszystko dlatego, by zwrócić uwagę np. na niedorzeczność pytania (skądinąd bardzo szkodliwego intelektualnie), do znudzenia zadawanego przez kolejne pokolenia nauczycieli kolejnym pokoleniom uczniów, o wyższości książki nad innymi formami medialnymi" ${ }^{17}$. (Nie)czystość owa dotyczy bowiem również i literatury, która, pozostając w związku z dziełem filmowym i grą komputerową, nierzadko stanowi jedną spójną narrację.

W takim ujęciu dzieło literackie/filmowe/gra wideo są już nie tyle tekstem, ile - jak je określa Filiciak - „paratekstem”. Wymownym tego przykładem może być choćby gra „Dying Light” wrocławskiego studia Techland. Aby udzielić sobie odpowiedzi na wiele jakkolwiek podstawowych pytań związanych z fabułą gry, musimy sięgnąć do powieści Raymonda Bensona Dying Light. Aleja Koszmarów, która ukazała się wraz z grą, jako właściwy wstęp do niej ${ }^{18}$.

Wszystko to sprawia, że - jak powiada Lech Witkowski - to, o co powinniśmy pytać w pierwszej kolejności, to „[...] do jakiego typu postawy wdrażamy

M. Filiciak Media, wersja beta..., s. 82.

17 Podobne pytania zadaje się uczniom nie tylko przy okazji szkolnych wypracowań, ale i - co gorsza - także egzaminów maturalnych. jeszcze trafnych przykładów, ilustrujących zjawisko paratekstualności. Jeśli więc sam powołuję się w tym miejscu na własny przykład, to czynię to przede wszystkim z myślą o tych, którzy po książkę M. Filiciaka sięgną dopiero po lekturze (i być za sprawą) niniejszego tekstu. Zob. R. Benson Dying Light. Aleja koszmarów, Zysk i S-ka, Poznań 2015. 
w toku edukacyjnego posługiwania się tekstami, uczniów szkół średnich czy studentów szkół wyższych, w tym jaki użytek uczymy ich robić z tekstów, które wezmą do ręki" ${ }^{19}$. Utrwaloną w ten sposób relację użytkowania "tekstu” nazywa dalej Witkowski „tekstualizacją doświadczenia”. Perspektywa taka zakłada, że ważniejsze od tego, „co tekst robi z użytkownikiem” (popularne i zwykle banalizowane pytanie dotyczące ewentualnego „wpływu”), jest to, „co użytkownik potrafi zrobić z tekstem". Pisane przez fanów równie głośnej gry „The Last of Us” nieoficjalne pamiętniki - nierzadko na wysokim poziomie literackim - ukazujące dalsze losy Joela i Ellie (głównych bohaterów tej gry) mogą stanowić znakomitą i inspirującą dydaktycznie tego ilustrację.

Na gruncie tego, co dydaktycy nazywają procesami „uczenia się"/,nauczania”, oznacza to, że nośnikiem równie „ważnych" i „poważnych” znaczeń może okazać się nie tylko od zawsze uprzywilejowane pod tym względem dzieło literackie czy mimo wszystko nadal nie zawsze "na serio" traktowane dzieło filmowe, ale i przez zdecydowaną większość nauczycieli wciąż jeszcze pojmowana jako forma , jarmarcznej rozrywki" gra wideo ${ }^{20}$. Tymczasem ta ostatnia, o czym znakomicie pisze choćby Rafał Kochanowski (notabene nauczyciel języka polskiego), mimo swojego ludycznego charakteru jest przecież także tekstem „[...] nacechowanym ideologicznie. Może wyrażać zarówno wszystko to, co szlachetne, jak i to, co szokuje bestialstwem"21.

Pozostając jeszcze przez chwilę przy temacie związanym nie tylko z procesami remediacji oraz paratekstualności, ale i tego wszystkiego, co znajduje się zarówno "między”, jak i „poza” nimi, warto za autorem Media, wersja beta... przywołać niezwykle istotną z punktu widzenia tych kategorii uwagę Haidee Wasson. Badaczka, rekapitulując strategię biznesową największych wytwórni

19 L. Witkowski Między pedagogikq, filozofią i kulturq̨. Studia, eseje, szkice, Wydawnictwo Instytutu Badań Edukacyjnych, Warszawa 2007, s. 35 .

20 Oczywiście ze względu na ergodyczny charakter gier wideo badanie ich (oraz doświadczenia samego gracza) nie może opierać się na analizach literaturoznawczych czy filmoznawczych. Nie zmienia to jednak faktu, że już samo pytanie, „w jaki sposób badać gry?”, może być odczytywane właśnie jako "tekstualizacja doświadczenia” i może stanowić dydaktycznie płodne wyzwanie. Inspiracji pod tym względem dostarcza w swoich pracach także lan Bogost, twórca tzw. retoryki proceduralnej, tj. metody analizy gier wideo wyraźnie w moim przekonaniu korespondującej z tym, co za Witkowskim nazywam tutaj „tekstualizacją doświadczenia”. Więcej na ten temat w: I. Bogost Gry informacyjne. Dziennikarstwo epoki cyfrowej, Wydawnictwo U), Kraków 2012.

21 R. Kochanowski Fabularyzowane gry komputerowe w przestrzeni humanistycznej. Analizy, interpretacje i wnioski z pogranicza poetyki, aksjologii i dydaktyki literatury, Wydawnictwo Naukowe, Poznań 2012. 
filmowych, podkreśla, że „[...] Vivendi-Universal i Viacom doskonale wiedzą, że film (movie) to nigdy nie jest tylko taśma (film). To także ścieżka dźwiękowa, pudełko na drugie śniadanie, czapka z daszkiem, gra wideo, produkcja dla kablówki, plastikowa figurka i DVD. Ten prosty fakt łączy tak zwany przemysł filmowy - tak samo jak łączy miliony osób, które oglądają, grają, przewijają, pauzują, ściągają, słuchają kolekcjonują wchodzą z kinem w inne interakcje"22; i dalej (już komentarz Filiciaka): „Jak widać, perspektywa, skoncentrowana na taśmie filmowej i kinie, także w ujęciu ekonomicznym, nie jest już kluczem do rozumienia kultury mediów - o ile kiedykolwiek nim była"23.

Uwagi zarówno Wasson, jak i samego Filiciaka można z powodzeniem odczytywać jako parafrazę dobrze już znanej pedagogom (szczególnie związanym z tzw. orientacją krytyczną) tezy, zgodnie z którą program szkolny nigdy nie jest wyłącznie tym, co zostało oficjalnie sformułowane w wymaganiach programowych. To także całość swoistej kultury szkolnej z charakterystycznymi dla niej rytuałami i artefaktami. Tym bardziej więc zaskakuje fakt, że nie znajdziemy w indeksie rzeczowym (mimo wszystko bardzo dobrze opracowanego) podręcznika akademickiego Pedagogika medialna pod redakcją Bronisława Siemienieckiego pojęć, o których mowa, tj. właśnie „paratekstualność" $\mathrm{i}$ „remediacja”24.

Ostatecznie (do)powiedzieć muszę, że nawet jeśli tekst niniejszy nie jest recenzją Media, wersja beta..., a przynajmniej nie jest nią w tradycyjnym tego słowa znaczeniu, to nie mam zamiaru ukrywać, że towarzyszyła mi ambicja, aby takową właśnie był. Ambicję tę konsekwentnie jednak ostudza sam autor Media, wersja beta..., z każdą kolejną stroną uświadamiając czytelnikowi, jak bardzo w istocie niejednoznaczna, złożona i dyskusyjna jest natura badanych przez niego zjawisk, co tylko utwierdza mnie w przekonaniu, że "na serio" napisana recenzja książki, o której tu mowa, musiałaby być w zasadzie osobną książką. Niechaj więc fakt ten usprawiedliwia mnie ostatecznie zarówno przed czytelnikiem, jak i samym Filiciakiem i niechaj też będzie odpowiedzią na pytanie, dlaczego przy okazji niniejszego tekstu skoncentrowałem się wyłącznie na kilku tylko (może nawet wcale nie reprezentatywnych dla tej książki) zagadnieniach, w przypadku których i tak pozwalam sobie na z pewnością przesadne niekiedy - uproszczenia.

M. Filiciak Media, wersja beta..., s. 182.

23 Tamże.

24 Nie znajdziemy w nim zresztą wielu innych, ważnych z punktu widzenia medialnego ekosystemu, pojęć i kategorii. 
Jednocześnie to, w jaki sposób Filiciak omawia kluczowe dla przedmiotu swoich dociekań problemy i zagadnienia, konsekwentnie dowodzi również tego, że nie jest to książka napisana po to, aby kogokolwiek „pouczyć”, a jedynie - choć i to nie zawsze - „oduczyć" (i to mimo że autor jej doskonale zdaje sobie sprawę z tego, że to ostatnie jest zdecydowanie trudniejsze od tego pierwszego). I nawet jeśli nie zawsze jestem skłonny zgadzać się z Mirosławem Filiciakiem w sprawach zasadniczych (trochę niesprawiedliwie poświęca autor kulturze obrazu nieproporcjonalnie więcej miejsca niż kulturze dźwięku), to i tak gratuluję mu równie mocno, jak mocno mu Media, wersja beta... zazdroszczę.

\section{Abstract}

\section{Łukasz Androsiuk}

POMERANIAN ACADEMY (StUPSK)

First and Foremost about Paratexuality and Remediation

Review: M. Filiciak, Media, wersja beta: Film i telewizja w czasach gier komputerowych [Media, Beta: Film and Television in the Days of Computer Games], Wydawnictwo Naukowe Katedra, Gdańsk 2013, 312 pp.

\section{Keywords}

culture 2.0, paratextuality, remediation, convergence, new media 